\title{
TUMOR ESTROMAL DO TRATO GASTRINTESTINAL PRIMÁRIO DA PAPILA DUODENAL
}

\section{GASTROINTESTINAL STROMAL TUMOR PRIMARY OF THE DUODENAL PAPILLA}

\author{
Luiz Fernandes Ferreira, ACBC-MS ${ }^{1}$ \\ Alberto de Oliveira Rosa Pires ${ }^{2}$ \\ Fábio Kanomata, TCBC-MS ${ }^{3}$
}

\section{INTRODUÇÃO}

Os tumores do trato gastrintestinal originários de células mesenquimais atualmente têm sido denominados Tumores Estromais Gastrintestinais (TEG), substituindo e abrangendo várias outras designações como leiomioma, leiomioblastoma, leiomiossarcoma e leiomioma epiteliói$\mathrm{de}^{1}$. São definidos por suas características imunohistoquímicas e genéticas típicas, diferentes dos verdadeiros leiomiomas e schwanomas ${ }^{1,2}$.

Apresentamos um caso de TEG em localização incomum, na região da papila duodenal, causando hemorragia digestiva alta e que foi tratado com gastroduodenopancreatectomia (GDP).

Além da raridade da doença ressaltamos a dificuldade no diagnóstico, principalmente na histopatologia da biopsia, e a decisão quanto ao melhor tratamento a ser instituído devido a incerteza na determinação da natureza benigna ou não da lesão e escassez na literatura em relação a tal conduta.

\section{RELATO DO CASO}

Paciente do sexo feminino, 33 anos, apresentando fezes enegrecidas há seis meses e anemia. Era portadora de hipertensão arterial sistêmica secundária a coarctação aórtica sob controle clínico com anti-hipertensivos e inibidores da adesividade plaquetária. As endoscopias digestivas alta e baixa previamente realizadas estavam normais.

Foi submetida a tomografia computadorizada de abdome que demonstrou tumor com cerca de 4,0cm de diâmetro na topografia de arco duodenal em íntimo contato com a cabeça do pâncreas, sugerindo neoplasia de papila duodenal (Figura 1). Uma nova endoscopia digestiva alta foi realizada com biópsia da papila e o exame anatomopatológico foi compatível com leiomioma.

Frente a este diagnóstico associado ao quadro de hemorragia digestiva alta, foi submetida à laparotomia exploradora com achado de massa tumoral na região do arco duodenal, rechaçando e aderente à cabeça do pâncreas. O inventário do restante da cavidade foi normal. Realizou-se uma GDP e reconstrução utilizando alça única de jejuno com anastomoses pancreatojejunal terminoterminal, coledocojejunal terminolateral e gastrojejunal oralis parcialis terminolateral, nesta seqüência.

A paciente teve boa evolução pós-operatória com alta no sétimo dia pós-operatório. Os exames anatomopatológico e imuno-histoquímico da peça demonstraram tratarse de um TEG com baixo número de mitoses, sugerindo benignidade (Figura 2).

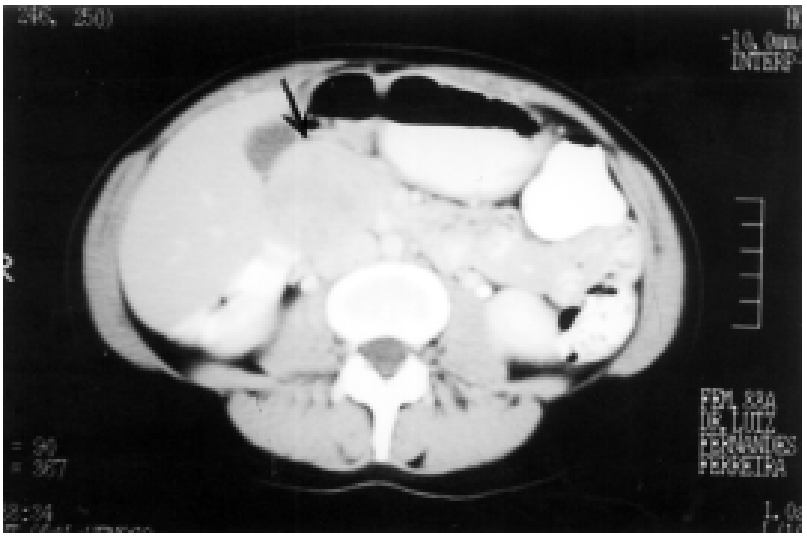

Figura 1 - Tomografia computadorizada de abdome mostrando tumor em topografia de arco duodenal.

1. Chefe do Serviço de Cirurgia do Aparelho Digestivo da Clinica de Campo Grande, Hospital e Centro Cardiorrespiratório, PROCARDIO, Campo Grande, MS. Diretor do Hospital São Julião

2. Cirurgião do Serviço de Cirurgia do Aparelho Digestivo na Clínica de Campo Grande, Hospital e Centro Cardiorrespiratório, PROCARDIO, Campo Grande, MS

3. Cirurgião Oncológico especializado pelo PRM do Instituto Nacional de Câncer - INCa, Título de Especialista em Cancerologia (TECA) pela Sociedade Brasileira de Cancerologia

Recebido em 10/04/2002

Aceito para publicação em 17/09/2002

Trabalho realizado Serviço de Cirurgia do Aparelho Digestivo na Clinica de Campo Grande, Hospital e Centro Cardiorrespiratório, PROCARDIO, Campo Grande, MS 


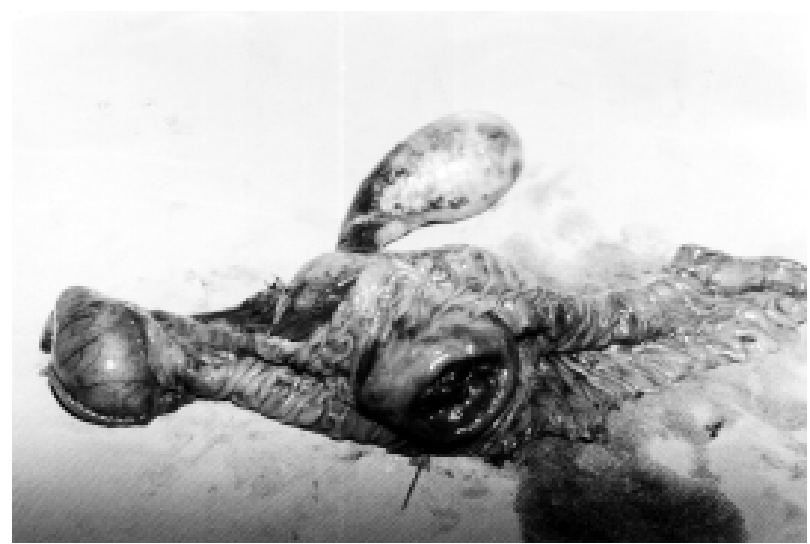

Figura 2 - Produto de gastroduodenopancreatectomia com luz duodenal aberta mostrando tumor ulcerado de papila.

\section{DISCUSSÃO}

As lesões do trato digestivo atualmente classificadas como TEG compreendem uma diversidade de tumores que tiveram suas características imuno-histoquímicas diferenciadas do que anteriormente se classificava como tumores de células musculares lisas ${ }^{1,2}$. Para o cirurgião a aplicação desta classificação está na determinação da natureza benigna ou maligna da lesão, seu prognóstico e, conseqüente a isso, o grau de radicalidade a ser empregado no tratamento.

Os TEG ocorrem em pacientes na meia-idade ou idosos, são mais comumente encontrados no estômago, depois intestino delgado e menos freqüentemente no esôfago, cólon e reto ${ }^{3}$. O quadro clínico está relacionado ao efeito de massa tumoral. No caso relatado, a paciente era jovem e a manifestação foi eminentemente hemorragia digestiva alta causada pela ulceração do tumor. Surpreendeu-nos a ausência de icterícia, tanto no exame físico como na história pregressa.

Além do diagnóstico inusitado de leiomioma de região papilar, a confusão na atual definição histopatológica de TEG foi o grande fator de dúvida quanto à conduta a ser tomada pois tratava-se de tumor volumoso de papila, porém com diagnóstico sugestivo de benignidade. $\mathrm{O}$ fator decisivo para indicação cirúrgica foi o quadro de descompensação por sucessivos episódios de hemorragia digestiva alta.

A literatura é escassa, porém há relato de séries limitadas de tratamento com excisão local via transduodenal para lesões benignas até $3 \mathrm{~cm}$, proposta por Jaeck ${ }^{4}$. A cirurgia de Whipple, que historicamente tem morbimortalidade elevada, vem, nos últimos anos, apresentando excelentes resultados, com baixo índice de complicações.

Frente a todos esses dados, a definição final da cirurgia realizada foi tomada no intra-operatório, até porque, eventualmente, o diagnóstico de malignidade pode ser feito pelo achado de implante peritoneal ${ }^{5}$. Levando-se em conta a necessidade de preservar os princípios de radicalidade cirúrgica oncológica, foi realizada a GDP sem preocupação com linfadenectomia, já que a literatura não traz dados a respeito desse procedimento para TEG em sua definição mais recente.

Muito embora o laudo anatomopatológico sugira benignidade, somente o seguimento determinará o prognóstico do caso. Concluímos que a abordagem realizada teve excelentes resultados pós-operatórios. Embora não se trate de doença comum, a escassez da literatura sobre o assunto provavelmente deve-se à confusão na classificação histopatológica ainda existente para os tumores primitivos de parede do trato gastrintestinal e a reformulação com base em achados imuno-histoquímicos.

\begin{abstract}
The majority gastrointestinal wall tumors previously considered leiomyomas or leiomyosarcomas were reclassified into Gastrointestinal Stromal Tumours because of typical imunohistochemic, genetic and biologic behaviors findings. We present a case report of Gastrointestinal Stromal Tumor primary of the duodenal papilla causing digestive haemorrage that was submitted to surgical treatment.
\end{abstract}

Key Words: Gastrointestinal Stromal Tumor; Duodenal papilla; Gastroduodepancreatectomy.

\title{
REFERÊNCIAS
}

1. Miettinem M, Sarlomo-Ricala M, Lazota J. Gastrointestinal stromal tumor: recent advances in understanding of their biology. Human Pathology, October 1999, Vol 30 No. 10:1213-1220

2. Allander SV, Nupponen NN, Ringner M et al. Gastrointestinal stromal tumors with KIT mutations exhibit a remarkably homogeneous genes expression profile. Cancer Res 2001 Dec 1 5;61 (24):8624-8

3. Strickland L, Letson GD, Muro-Cacho CA. Gastrointestinal stromal tumors. Cancer Controi 2001 May-Jun; 8(3): 252-61.

4. Jaeck D, Boudjema K, Bacheilier P et al. Exéresis de los tumores periampulares. Encicl. Med. Chir. (Eisevier,
Paris-France ), Técnicas quirurgicas do aparato digestivo: 40-880-c, 1998, 6p

5. Nishida T, Hirota S. Biological and clinical review of stromal tumors in the gastrointestinal tract. Histol Histopathol 2000 oct; 15(4): 1293-301.

Endereço para correspondência:

Luiz Fernandes Ferreira

Rua Ana Lúcia, 203 - Giocondo Orsi

79022-520 - Campo Grande,MS

E-mail:luiz.s@terra.com.br 